Article

\title{
High Genetic Diversity in Geographically Remote Populations of Endemic and Widespread Coral Reef Angelfishes (genus: Centropyge)
}

\author{
Jean-Paul A. Hobbs ${ }^{1, *}$, Lynne van Herwerden ${ }^{2,3}$, Dean R. Jerry ${ }^{2,3}$, Geoffrey P. Jones ${ }^{3,4}$ and \\ Philip L. Munday ${ }^{3,4}$
}

1 The Oceans Institute and School of Plant Biology, The University of Western Australia, Crawley 6009, Australia

2 Molecular Ecology and Evolution Laboratory, James Cook University, Townsville, 4811, Australia;

E-Mails: Lynne.vanherwerden@jcu.edu.au (L.H.); dean.jerry@jcu.edu.au (D.R.J.)

3 School of Marine and Tropical Biology, James Cook University, Townsville, 4811, Australia;

E-Mails: geoffrey.jones@jcu.edu.au (G.P.J.); philip.munday@jcu.edu.au (P.L.M.)

4 ARC Centre of Excellence for Coral Reef Studies, James Cook University, Townsville, 4811, QLD, Australia

* Author to whom correspondence should be addressed; E-Mail: jean-paul.hobbs@uwa.edu.au; Tel.: +6-18-6488-4648; Fax: +6-17-4725-1570.

Received: 8 January 2013; in revised form: 21 January 2013 / Accepted: 25 January 2013 / Published: 4 February 2013

\begin{abstract}
In the terrestrial environment, endemic species and isolated populations of widespread species have the highest rates of extinction partly due to their low genetic diversity. To determine if this pattern holds in the marine environment, we examined genetic diversity in endemic coral reef angelfishes and isolated populations of widespread species. Specifically, this study tested the prediction that angelfish (genus: Centropyge) populations at Christmas and Cocos Islands have low genetic diversity. Analyses of a 436 base pair fragment of the mtDNA control region revealed that the endemic $C$. joculator exhibited high haplotype ( $h>0.98$ at both locations) and nucleotide (Christmas $\pi \%=3.63$, $\operatorname{Cocos} \pi \%=9.99)$ diversity. Similarly, isolated populations of widespread angelfishes (C. bispinosa and C. flavicauda) had high haplotype $(h>0.98)$ and nucleotide $(\pi \%=2.81$ and $\pi \%=5.78 \%$, respectively) diversity. Therefore, in contrast to terrestrial patterns, endemic and isolated populations of widespread angelfishes do not have low genetic diversity, rather their haplotype and nucleotide diversities were among the highest reported for marine fishes. High genetic diversity should reduce extinction risk in these species as it
\end{abstract}


could provide the evolutionary potential to adapt to the rapidly changing environmental conditions forecast for coral reefs.

Keywords: extinction risk; haplotype diversity; nucleotide diversity; Pomacanthidae; Christmas Island; Cocos (Keeling) Islands

\section{Introduction}

The highest rates of extinction have been recorded for endemic species and populations of widespread species inhabiting islands [1-3]. The high risk of extinction in this group has been attributed to a range of demographic, environmental and genetic factors $[1,2,4]$. The genetic characteristics that increase extinction risk in this group are low genetic diversity and inbreeding depression [1,2]. Low genetic diversity increases extinction risk because it reduces the potential for species to adapt to rapid environmental change. In endemics, and isolated populations of widespread species, inbreeding depression is thought to occur because of the low number of individuals forming the founder population and the small size of the extant population [5,6]. The importance of maintaining genetic diversity to reduce extinction risk is recognised by the IUCN and is considered to be a conservation priority $[6,7]$.

Genetic diversity can be influenced by a range of factors including population size, natural selection, mutation rates, gene flow between populations, introgression from hybridisation and historical effects on these factors (e.g., population bottlenecks) [6]. In the terrestrial environment, island endemic species usually have small populations [5,8] and consequently, genetic diversity is predicted to be low as genetic variation is increasingly lost through genetic drift [9]. Isolated island populations of widespread species are also expected to have low genetic diversity because of limited gene flow with other populations and lower localised effective population sizes $[6,10]$. Therefore, low genetic diversity is expected to be a feature of terrestrial communities on remote islands because they contain a high proportion of endemic species and isolated populations of widespread species.

Coral reef fishes are the most diverse vertebrate communities in the world and are found throughout the tropics, including numerous remote islands. These isolated islands are hotspots of coral reef fish endemicity [11-14] and also support isolated populations of species with broad geographic ranges. Determining whether these endemics and isolated populations conform to terrestrial patterns of low genetic diversity is crucial to assessing their risk of extinction. Of the known neo-extinctions of reef fishes, all have been from isolated islands or island groups $[15,16]$. An appreciation of the genetic diversity of endemic reef fishes is also of importance for ascertaining extinction risk of this group to changes in their environment caused by local and global anthropogenic disturbances $[17,18]$.

Previous studies have revealed a range of genetic diversity values for populations of marine fishes, including those inhabiting coral reefs. Haplotype diversity $(h)$ in populations of marine fishes has been found to vary vastly from 0 to 1 , while nucleotide diversity $(\pi \%)$ is known to vary from 0.07 to 31.8 [19-23]. For marine fishes, haplotype and nucleotide diversities are generally considered to be low where $h$ and $\pi \%$ are less than 0.5 [19]. Therefore, if reef fishes conformed to predictions based on 
terrestrial fauna, we would expect endemic species, and isolated populations of widespread fishes, to have low haplotype $(h<0.5)$ and nucleotide $(\pi<0.5 \%)$ diversities.

This study determines whether endemic and isolated populations of widespread angelfishes, at Christmas and Cocos Islands have low genetic diversity $(h<0.5$ and $\pi<0.5 \%)$. These islands are an ideal location to examine genetic diversities of isolated marine species because they are among the most-isolated islands in the tropical Indian Ocean [24]. Three congeneric pygmy angelfish (genus: Centropyge) species were examined. Centropyge joculator is endemic to these two locations and is not found anywhere else in the world [25]. C. bispinosa and C. flavicauda are among the most widely distributed angelfishes, ranging from east Africa to the central Pacific Ocean [25], with Christmas Island supporting geographically-isolated populations of these species. Christmas and Cocos Islands are separated by approximately $1000 \mathrm{~km}$, therefore, we also predicted that the two populations of the endemic species ( $C$. joculator) might be genetically subdivided between these locations due to low genetic exchange [26].

\section{Experimental Section}

\subsection{Field Collections}

Genetic material for this study was obtained by collecting angelfishes from both Christmas $\left(10^{\circ} 29^{\prime} \mathrm{S}, 107^{\circ} 37^{\prime} \mathrm{E}\right)$ and Cocos (Keeling) Islands $\left(12^{\circ} 04^{\prime} \mathrm{S}, 96^{\circ} 48^{\prime} \mathrm{E}\right)$. Individuals of $C$. joculator were collected from both locations (Christmas $n=44$ and Cocos $n=41$ ). Samples of the widespread study species were only collected from Christmas Island $(\mathrm{n}=24$ for $C$. bispinosa and $\mathrm{n}=28$ for $C$. flavicauda), as they are absent from the Cocos Islands. All angelfishes were collected by spearfishing whilst SCUBA diving in May to August 2005 . Shortly after capture, a small fin clip $\left(\sim 1 \mathrm{~cm}^{2}\right)$ was taken from each fish and preserved separately in $80 \%$ ethanol.

\subsection{Laboratory Procedures}

The mitochondrial (mtDNA) control region (D-loop) was used to determine genetic diversity of endemic and isolated populations of widespread angelfishes. Samples were washed in TE buffer and DNA was obtained by first digesting with Proteinase $\mathrm{K}$ followed by standard salt $(\mathrm{NaCl})$ extraction [27]. Amplification of a 436 base pair section of the mtDNA control region was performed using universal primers LI5995 (5'-AATTCTCACCCCTAGCTCCCAAAG-3') and HI6498 (5'-CCTGAAGTAGGAACCAGATG-3') [28]. Amplification involving polymerase chain reaction (PCR) was conducted using a $20 \mu \mathrm{l}$ volume containing the following reagents: $2.5 \mathrm{mM}$ Tris $\mathrm{pH} 8.7$, $5 \mathrm{mM} \mathrm{KCl}, 5 \mathrm{mM}\left(\mathrm{NH}_{4}\right)_{2} \mathrm{SO}_{4}, 200 \mu \mathrm{M}$ each dNTP, $2 \mathrm{mM} \mathrm{MgCl}_{2}, 0.5 \mu \mathrm{M}$ forward primer LI595, $0.5 \mu \mathrm{M}$ reverse primer HI6498, $1 \mathrm{U}$ Taq polymerase (Qiagen), and at least $10 \mathrm{ng}$ of DNA template. The PCR was conducted as follows: a denaturing step of $94{ }^{\circ} \mathrm{C}$ for $30 \mathrm{sec}$, followed by an annealing temperature of $51{ }^{\circ} \mathrm{C}$ for $30 \mathrm{sec}$, then $72{ }^{\circ} \mathrm{C}$ for $90 \mathrm{sec}$ and a final extension of $72{ }^{\circ} \mathrm{C}$ for $10 \mathrm{~min}$, This cycle was repeated 34 times. The success of PCR reactions was verified after running $2 \mu \mathrm{L}$ of PCR product through a $2 \%$ agarose gel. The gel also revealed a single band of PCR product and a ladder verified that the amplified DNA fragment was the correct size. The remaining PCR product was cleaned using isopropanol, dried and sent to Macrogen Inc. (Seoul, Korea) for standard Sanger 
sequencing. Both the forward and reverse sequences were obtained using primers LI5995 and HI6498 (respectively).

\subsection{Data Analyses}

To determine genetic diversity, sequences were first visually aligned using Sequencher 4.5 (Gene Code Corporation, MI, USA), and then manually adjusted in BioEdit (Version 7.0.9) [29] in preparation for importing into molecular statistical programs.

Arlequin (version 2.0), [30] was used to calculate haplotype diversity index $(h)$, nucleotide diversity index $(\pi \%)$ and the number of nucleotide changes as input for constructing a minimum spanning tree of the haplotype network [31] for each of the three study species. Haplotype diversity index followed Nei [32] where $h=n\left(1-\sum x_{\mathrm{i}}^{2}\right) /(n-1)$, and $n$ is the total number of individuals and $x_{\mathrm{i}}$ is the frequency of a given haplotype in the population. For the endemic $C$. joculator, haplotype and nucleotide diversity were calculated for each of the two populations (Christmas and Cocos), as well as for the total (i.e., both populations combined). Genetic population structure was examined in C. joculator using analysis of molecular variance (AMOVA) conducted in Arlequin. For the widespread species (C. bispinosa and C. flavicauda), haplotype and nucleotide diversity values were calculated for Christmas Island populations.

Phylogenetic analyses were also undertaken to determine how evolutionary history affects genetic diversity in C. joculator. Neighbour joining (NJ, Tamura-Nei model, 1000 bootstrap replicates) and Maximum Parsimony (MP) approaches were used to construct a phylogram in MEGA (Molecular Evolutionary Genetics Analysis, Version 4.0), [33]. Maximum Likelihood (ML) analyses were also performed in GARLI (Genetic Algorithm for Rapid Likelihood Inference), [34]. Ten independent ML analyses were run, each comprised of 10,000 generations, with the best tree determined by the lowest log-likelihood score. Information from the best tree was imported into PAUP (Phylogenetic Analysis Using Parsimony, version 4.0), [35] to produce a 50\% consensus tree with NJ and MP support values added to the tree nodes. The tree was rooted using C. bispinosa and C. flavicauda as the outgroups.

\section{Results}

\subsection{Endemic C. joculator}

Examination of the $436 \mathrm{bp}$ control region mtDNA sequenced from 85 C. joculator individuals (Christmas $n=44$ and Cocos $n=41$ ) revealed 161 polymorphic sites, 143 transitions, 42 transversions and 8 indels. The AT:CG ratio was biased 31:19. There were 54 unique haplotypes and 12 shared haplotypes (shared between 2 to 6 individuals) (Figure 1). Haplotype diversity was high $(h>0.98)$ in both the Christmas and Cocos populations (Table 1). Nucleotide diversity was also high for both populations $(\pi \%=3.63$ and 9.99 for Christmas and Cocos respectively) due to the high number of pairwise differences between individuals arising from the large number of base pair substitutions (Table 1).

Phylogenetic analyses revealed two distinct groups within the endemic species (Figure 1), with an ancestral group comprised of 10 individuals found only at the Cocos Islands. The second group (the more recently diverged group) contained fish from both Christmas and Cocos, and included the 
majority of the sampled individuals (75 of 85). The 10 individuals in the ancestral group all had unique haplotypes, and haplotype diversity was also high in the more recently derived group $(h>0.98)$, although there were 12 shared haplotypes. Nucleotide diversity was high for both groups $(\pi \%=3.34$ to 3.66, Table 1).

There was a significant difference in the haplotype frequency of the Christmas and Cocos populations of $C$. joculator $\left(\Phi_{\mathrm{ST}}=0.011, p=0.0007\right)$. This difference may have been driven by the presence of the localised ancestral group at the Cocos Islands. However, re-analysing the data without the ancestral group (10 Cocos individuals removed) showed that the Christmas and Cocos populations remain genetically differentiated, indicating restricted gene flow between the two populations $\left(\Phi_{\mathrm{ST}}=0.013, p=0.001\right)$.

Figure 1. (a) Outgroup rooted phylogram based on $436 \mathrm{bp}$ control region mtDNA sequences from 85 Centropyge joculator individuals (44 from Christmas Island and 41 from the Cocos Islands). The NJ, MP and ML majority rule bootstrap consensus support values are displayed at each node. (b) Minimum spanning tree of $C$. joculator haplotypes. Black filled circles are Christmas Island individuals and unfilled circles are individuals from the Cocos Islands. The size of the circle indicates the relative frequency of each haplotype ( smallest circle $=1$ individual, largest circle $=6$ individuals). Bars indicate the number of substitutions between haplotypes, with thin bars $=1$ substitution, medium bars $=$ 5 substitutions, and thick bars $=10$ substitutions. (c) Mismatch distribution of pairwise sequence differences for $C$. joculator and the expected distribution of pairwise sequence differences under an expansion model.

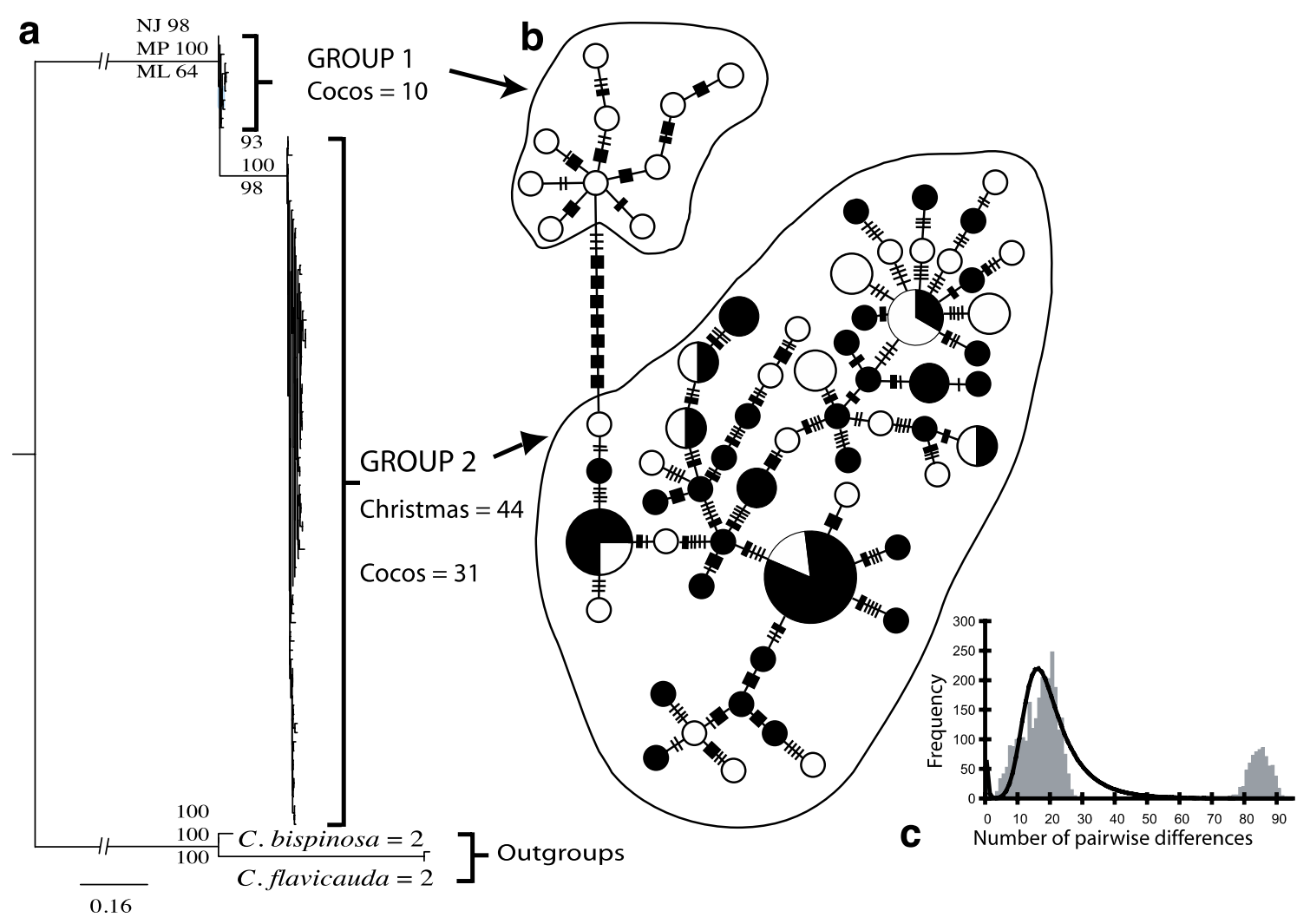


Table 1. Genetic diversity measures for the endemic Centropyge joculator from Christmas and Cocos Islands, and for the widespread species C. bispinosa and C. flavicauda from Christmas Island.

\begin{tabular}{lcccccc}
\hline Species & Location & $\boldsymbol{n}$ & $\boldsymbol{n}_{\mathbf{h}}$ & $\boldsymbol{h}( \pm \mathbf{S D})$ & $\pi \%( \pm$ SD) & $\begin{array}{c}\text { Mean pairwise } \\
\text { differences }( \pm \text { SD) }\end{array}$ \\
\hline C. flavicauda & Christmas Island & 28 & 28 & $1 \pm 0.010$ & $2.81 \pm 0.39$ & $12.08 \pm 5.63$ \\
C. bispinosa & Christmas Island & 24 & 23 & $0.989 \pm 0.012$ & $5.78 \pm 0.73$ & $24.04 \pm 10.95$ \\
$\begin{array}{l}\text { C. joculator } \\
\text { C. joculator }\end{array}$ & $\begin{array}{c}\text { Christmas Island } \\
\text { Cocos Islands }\end{array}$ & 44 & 35 & $0.983 \pm 0.011$ & $3.63 \pm 1.83$ & $15.70 \pm 7.14$ \\
C. joculator & $\begin{array}{c}\text { Christmas and Cocos } \\
\text { Islands }\end{array}$ & 85 & 66 & $0.991 \pm 0.004$ & $6.92 \pm 0.34$ & $30.16 \pm 13.30$ \\
C. joculator & $\begin{array}{c}\text { Group 1 (Cocos } \\
\text { Islands) }\end{array}$ & 10 & 10 & $1 \pm 0.045$ & $3.34 \pm 1.85$ & $14.49 \pm 7.10$ \\
C. joculator & $\begin{array}{c}\text { Group 2 (Christmas } \\
\text { and Cocos Islands) }\end{array}$ & 75 & 56 & $0.988 \pm 0.005$ & $3.66 \pm 1.83$ & $15.83 \pm 7.14$ \\
\hline
\end{tabular}

$n=$ number of individuals, $n_{\mathrm{h}}=$ number of haplotypes, $h=$ haplotype diversity index. Nucleotide diversity is given as a percentage $(\pi \%)$ and standard deviations (SD) are provided.

\subsection{Widespread Species C. bispinosa and C. flavicauda}

A 436 bp section of the mtDNA control was successfully sequenced from 24 C. bispinosa individuals collected from Christmas Island. The sequences revealed 81 polymorphic sites, with 78 transitions, 2 tranversions, 4 indels and an AT:CG ratio of 7:3. Haplotype diversity was very high ( $h=0.99$ ) as 23 of the 24 sequenced individuals had unique haplotypes (Figure 2, Table 1). Nucleotide diversity in this isolated population was also very high $(\pi \%=5.78)$ due to the large number of base pair differences between individuals (mean $=24$, Table 1 , Figure $2 a$ ).

Figure 2. Minimum spanning tree for haplotypes of widespread species a) Centropyge bispinosa $(\mathrm{n}=24)$, and b) C. flavicauda $(\mathrm{n}=28)$ collected from Christmas Island. The size of the circle indicates the relative abundance of each haplotype (smallest circle $=1$ individual, largest circle $=2$ individuals). Bars indicate the number of substitutions between haplotypes, with thin bars $=1$ substitution, medium bars $=5$ substitutions, and thick bars $=10$ substitutions.
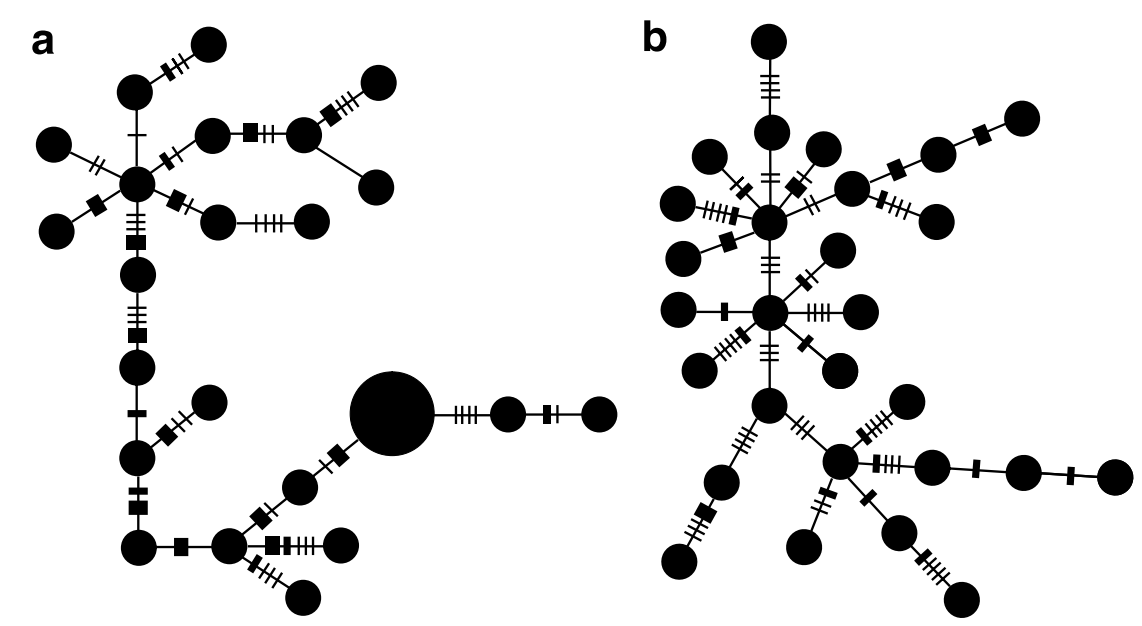
The same section of mtDNA was sequenced in 28 C. flavicauda individuals from Christmas Island. These sequences comprised 74 polymorphic sites, with 65 transitions, 8 transversions, 7 indels, and an AT:CG ratio of 31:14. All 28 individuals had a unique haplotype $(h=1)$, and nucleotide diversity was also high $(\pi \%=2.81)$ (Table 1 , Figure $2 b)$.

\section{Discussion}

In the terrestrial environment, genetic diversity of endemics and isolated populations of widespread species tends to be low and this may be an important factor contributing to their extinction risk [1,9]. Based on this, and the known range of genetic diversity for marine fishes [19], we predicted that island endemic reef fishes and isolated populations of species with broad geographic ranges would have low haplotype $(h<0.5)$ and nucleotide $(\pi<0.5 \%)$ diversity. Instead, we found that genetic diversity values of the endemic and isolated angelfish populations $(h>0.98, \pi>2.8 \%)$ were among the highest recorded for marine fishes [19,21-23,36-39]. Hence, contrary to expectations based on terrestrial species, it appears that there are processes operating that are promoting, rather than reducing, genetic diversity in these endemic and isolated populations.

There are a number of factors that influence genetic diversity. Endemic species usually have low abundance $[5,8]$ and therefore are predicted to have low genetic diversity because of the increasingly deleterious effects of inbreeding and genetic drift on small populations [9,40]. However, marine endemics often have high abundance [41] and thus the effect of drift on genetic diversity may be minimal. Indeed, the abundance of the endemic study species $C$. joculator is more than 30 times greater than that of the 16 widespread species of angelfishes that are present at Christmas and Cocos Islands [42]. High genetic and nucleotide diversity is expected in fishes that maintain large populations through their evolutionary history [19]. If the current high abundance of $C$. joculator has been a feature of its evolutionary history then this will have contributed to its high haplotype and nucleotide diversity.

Irrespective of population size, genetic diversity can also be high if endemics occur in refugia (e.g., Pleistocene refugia: [43]) where environmental conditions have been relatively stable over evolutionary time scales allowing for the accumulation of genetic variation (see [44] and references therein). Christmas and Cocos Islands are oceanic islands that have the Indonesian Archipelago as their nearest neighbour. Indonesia is an area where Pleistocene sea level fluctuations caused significant disruption to marine habitats and fauna [45]. If Christmas and Cocos Islands were environmentally stable then they may have served as Pleistocene refugia. Also, C. joculator may have had high genetic diversity if it was once more widespread and as its range contracted this diversity may have been condensed and maintained in the relict populations at Christmas and Cocos Islands. These islands also support endemic relict populations of other reef fishes (e.g., C. flavissima and Stegastes insularis, [25,46]) whose disjunct geographic ranges are separated by the historically tumultuous Indonesian Archipelago [45]. Therefore, the high genetic diversity of $C$. joculator at Christmas and Cocos may also be because it is endemic to refugia and/or because it is a relict of a once widespread species.

Endemics can also have high genetic diversity if they represent a fusion of clades or have interbred with other species (i.e., introgression from hybridisation) [47-50]. Christmas and Cocos Islands represents a suture zone where different clades or species come into secondary contact and interbreed $[51,52]$. C. joculator has both high haplotype and nucleotide diversity, which is a signature 
of secondary contact between different clades or lineages [19]. Indeed, two genetically distinct groups were detected in $C$. joculator and while the historical cause(s) for the origin of these groups is not known, it has clearly increased the genetic diversity of this species.

The restricted gene flow between Christmas and Cocos populations of $C$. joculator supports the notion that endemic reef fishes have limited dispersal [26]. Restricted gene flow may have also influenced genetic diversity in C. joculator. If local adaptation occurs at each island location then this will lead to differences in the gene pools of the two populations. Rare dispersal events may allow for enough gene flow to increase genetic diversity in each population, but gene flow may be insufficient to homogenise the genetic composition or to counteract adaptive changes of both populations.

Genetic diversity in isolated populations of widespread species is predicted to be low because population size is usually small and gene flow to other populations is low [1]. However, genetic diversity was high despite the very small population sizes observed for the two widespread study species at Christmas Island ( 0.05 to 0.18 individuals per $300 \mathrm{~m}^{2}$ : [42]). It is possible these isolated populations still receive sufficient gene flow from other populations because these species are among the most widely distributed angelfishes in the world [25] and gene flow would be required to establish and maintain this broad distributional range. Isolated populations of other widespread Centropyge species also have high haplotype diversity and high genetic connectivity [37,53]. Furthermore, the recent arrival of $C$. acanthops at the Cocos Islands (Hobbs personal observation) demonstrates that larvae of widespread Centropyge species are capable of dispersing over $2500 \mathrm{~km}$. Broad dispersal in widespread Centropyge may be facilitated by broadcast spawning, a pelagic larval duration of 30 to 35 days and competent swimming abilities of late stage larvae [54,55], which may be further aided by favorable currents at the time of spawning. Moderate to high genetic diversity (haplotype and/or nucleotide) has also been reported in several other widespread reef fishes present at Christmas and Cocos Islands [21-23,39]. The gene flow received by populations of these widespread species at Christmas and Cocos Islands may be sufficient to counteract the loss of genetic diversity associated with genetic drift. For the widespread species examined in this study, additional sampling from other populations would be required to confirm that gene flow was the reason for their high genetic diversity at Christmas Island.

Genetic diversity can also be related to taxonomy with some groups having higher diversity due to faster mutation rates [9]. High haplotype diversity in an Atlantic Centropyge angelfish was partly attributed to the high mutation rate of the control region of mtDNA [37]. Similarly, a very high rate of mutation rate has been detected in the mtDNA control region of butterflyfishes [56], which are the sister group to angelfishes [25,57]. Therefore, the high genetic diversity observed in all three angelfishes in this study is probably influenced (at least partly) by the fast mutation rate of the mtDNA control region in this taxonomic group.

In this study we used mtDNA to examine genetic diversity. A more detailed assessment of genetic diversity would require sequencing regions of the nuclear genome and developing microsatellites to estimate genotypic diversity from multiple independent loci. However, mtDNA diversity provides a reasonable proxy for nuclear diversity in marine fishes [58] and therefore we expect that the angelfishes in this study do not have low nuclear DNA diversity. Research on other coral reef fishes has used mtDNA control region and nuclear DNA and both markers produced comparable results: endemics have higher genetic diversity than widespread congeners [50]. The hypotheses of this study 
did not test if endemics and isolated populations of angelfishes had high genetic diversity, but rather tested if they had low genetic diversity (as per expectations based on terrestrial patterns). Despite the limitations of this study, we are confident that these hypotheses can be rejected (that is, endemics and isolated populations of angelfishes do not have low genetic diversity). Even though we did not sample central populations of the widespread species, it is evident just from sampling the isolated populations that isolated populations do not have low genetic diversity. Both nucleotide and haplotype diversity in the isolated populations are among the highest seen for reef fishes and approach the maximum possible.

\section{Conclusions}

This study found that geographically remote populations of endemic and widespread angelfishes had high genetic diversity and thus did not conform to terrestrial patterns of low genetic diversity. Endemic terrestrial species usually have low genetic diversity because they often have low abundance [1,9]. However, endemic reef fishes frequently have high abundance (reviewed in [41]) and therefore they may not have low genetic diversity. In the terrestrial environment, isolated populations of widespread species usually have low genetic diversity because they have small populations and low gene flow. However, the dispersive larval phase of reef fishes increases the potential for genetic exchange over large areas and this gene flow may be sufficient to maintain high genetic diversity in isolated populations [21-23]. Further research on the genetic diversity of endemic marine species and populations at remote locations is required to determine if there are differences in geographic patterns of genetic diversity between marine and terrestrial species. Determining patterns of genetic diversity is important because if geographically remote populations of endemic and widespread marine species have high genetic diversity than this should increase their evolutionary potential to adapt to escalating impacts $[17,18]$.

\section{Acknowledgments}

We greatly appreciate the field assistance of Jay Hender, Justin Gilligan, and the logistical support from Parks Australia, John Clunies-Ross and Geoff Christie. Special thanks to Selma Klanten, Peter Cowman, Adrian McMahon, Stephen Kolomyjec and David Jones for assistance with laboratory procedures and statistical analyses. We value the access to all required resources to undertake our genetic work in the Molecular Ecology and Evolution Laboratory at James Cook University. This research was partially funded by a James Cook University Competitive Research Incentive Grant to G. Jones, P. Munday and D. Jerry. J-P Hobbs was supported by a Nancy Vernon Rankine Award.

\section{References and Notes}

1. Frankham, R. Do island populations have less genetic variation than mainland populations? Heredity 1997, 78, 311-327.

2. Frankham, R. Inbreeding and extinction: Island populations. Conserv. Biol. 1998, 12, 665-675.

3. Whittaker, R.J. Island Biogeography: Ecology, Evolution, and Conservation; Oxford University Press: Oxford, UK, 1998. 
4. Pimm, S.L. The Balance of Nature: Ecological Issues in the Conservation of Species and Communities; University of Chicago Press: Chicago, IL, USA, 1991.

5. Gaston, K.J. Rarity; Chapman \& Hall: London, UK, 1994.

6. Frankham, R.; Ballou, J.D.; Briscoe, D.A. Introduction to Conservation Genetics; Cambridge University Press: Cambridge, UK, 2002.

7. McNeely, J.A.; Miller, K.R.; Reid, W.V.; Mittermeier, R.A.; Werner, T.B. Conserving the World's Biological Diversity; IUCN: Gland, Switzerland, 1990.

8. Gaston, K.J.; Blackburn, T.M.; Lawton, J.H. Interspecific abundance-range size relationships: An appraisal of mechanisms. J. Anim. Ecol. 1997, 66, 579-601.

9. Frankham, R. Relationship of genetic variation to population size in wildlife. Conserv. Biol. 1996, $10,1500-1508$.

10. Diamond, J. "Normal" extinctions of isolated populations. In Extinctions, Nitecki, M.H., Ed.; University of Chicago Press: Chicago, IL, USA, 1984; pp 191-246.

11. Randall, J.E. Zoogeography of shore fishes of the Indo-Pacific region. Zool. Stud. 1998, 37, 227-268.

12. Robertson, D.R. Population maintenance among tropical reef fishes: Inferences from small-island endemics. Proc. Natl. Acad. Sci. USA 2001, 98, 5667-5670.

13. Hughes, T.P.; Bellwood, D.R.; Connolly, S.R. Biodiversity hotspots, centres of endemicity, and the conservation of coral reefs. Ecol. Lett. 2002, 5, 775-784.

14. Jones, G.P.; Caley, M.J.; Munday, P.L. Rarity in coral reef fish communities. In Coral Reef Fishes: Dynamics and Diversity in a Complex Ecosystem; Sale, P.F., Ed.; Academic Press: San Diego, CA, USA, 2002; pp 81-101.

15. Roberts, C.M.; Hawkins, J.P. Extinction risk in the sea. Trends Ecol. Evol. 1999, 14, 241-246.

16. Dulvy, N.K.; Sadovy, Y.; Reynolds, J.D. Extinction vulnerability in marine populations. Fish Fish. 2003, 4, 25-64.

17. Bellwood, D.R.; Hughes, T.P.; Folke, C.; Nyström, M. Confronting the coral reef crisis. Nature 2004, 429, 827-833.

18. Munday, P.L.; Leis, J.M.; Lough, J.M.; Paris, C.B.; Kingsford, M.J.; Berumen, M.L.; Lambrechts, J. Climate change and coral reef connectivity. Coral Reefs 2009, 28, 379-395.

19. Grant, W.A.S.; Bowen, B.W. Shallow population histories in deep evolutionary lineages of marine fishes: Insights from sardines and anchovies and lessons for conservation. J. Hered. 1998, 89, 415-426.

20. Craig, M.T.; Eble, J.A.; Bowen, B.W.; Robertson, D.R. High genetic connectivity across the Indian and Pacific Oceans in the reef fish Myripristis berndti (Holocentridae). Mar. Ecol. Prog. Ser. 2007, 334, 245-254.

21. Klanten, O.S.; Choat, J.H.; Van Herwerden, L. Extreme genetic diversity and temporal rather than spatial partitioning in a widely distributed coral reef fish. Mar. Biol. 2007, 150, 659-670.

22. Horne, J.B.; Van Herwerden, L.; Choat, J.H.; Robertson, D.R. High population connectivity across the Indo-Pacific: Congruent lack of phylogeographic structure in three reef fish congeners. Mol. Phylogenet. Evol. 2008, 49, 629-638.

23. Gaither, M.R.; Toonen, R.J.; Robertson, D.R.; Planes, S.; Bowen, B.W. Genetic evaluation of marine biogeographical barriers: Perspectives from two widespread Indo-Pacific snappers (Lutjanus kasmira and Lutjanus fulvus). J. Biogeogr. 2010, 37, 133-147. 
24. Briggs, J.C. Marine zoogeography. McGraw-Hill: New York, NY, USA, 1974.

25. Allen, G.R.; Steene, R.C.; Allen, M. A guide to angelfishes \& butterflyfishes. Odyssey Publishing/Tropical Reef Research: Perth, Australia, 1998.

26. Eble, J.A.; Toonen, R.J.; Bowen, B.W. Endemism and dispersal: Comparative phylogeography of three surgeonfishes across the hawaiian archipelago. Mar. Biol. 2009, 156, 689-698.

27. Sambrook, J.; Fritsch, E.F.; Maniatis, T. Molecular cloning: A laboratory manual. Cold Spring Harbor Laboratory Press: New York, NY, USA, 1989.

28. Lee, W.J.; Conroy, J.; Howell, W.H.; Kocher, T.D. Structure and evolution of teleost mitochondrial control regions. J. Mol. Evol. 1995, 41, 54-66.

29. Hall, T. Bioedit: Biological Sequence Alignment; Ibis biosciences: Carlsbad, CA, USA, 2007.

30. Schneider, S.; Roessli, D.; Excoffier, L. Arlequin: A Software for Population Genetics Data Analysis; Genetics and Biometry Laboratory, University of Geneva: Geneva, Switzerland, 2000.

31. Rohlf, F.J. Algorithm 76. Hierarchical clustering using the minimum spanning tree. Comput. J. 1973, 16, 93-95.

32. Nei, M. Molecular evolutionary genetics. Columbia University Press: New York, NY, USA, 1987.

33. Tamura, K.; Dudley, J.; Nei, M.; Kumar, S. MEGA4: Molecular evolutionary genetics analysis (MEGA) software version 4.0. Mol. Biol. Evol. 2007, 24, 1596-1599.

34. Zwickl, D.J. Genetic algorithm approaches for the phylogenetic analysis of large biological sequence datasets under the maximum likelihood criterion. Ph.D. Thesis, The University of Texas, Austin, 2006.

35. Swofford, D.L. PAUP*: Phylogenetic analysis using parsimony, Sinauer Associates: Sunderland, MA, USA, 2003. Information confirmed correct

36. Bay, L.; Choat, J.H.; Herwerden, L.; Robertson, D.R. High genetic diversities and complex genetic structure in an Indo-Pacific tropical reef fish (Chlorurus sordidus): Evidence of an unstable evolutionary past? Mar. Biol. 2004, 144, 757-767.

37. Bowen, B.W.; Muss, A.; Rocha, L.A.; Grant, W.S. Shallow mtdna coalescence in atlantic pygmy angelfishes (genus Centropyge) indicates a recent invasion from the indian ocean. J. Hered. 2006, 97, 1-12.

38. Hickey, A.J.R.; Lavery, S.D.; Hannan, D.A.; Baker, C.S.; Clements, K.D. New zealand triplefin fishes (family tripterygiidae): Contrasting population structure and mtDNA diversity within a marine species flock. Mol. Ecol. 2009, 18, 680-696.

39. Winters, K.L.; van Herwerden, L.; Choat, J.H.; Robertson, D. Phylogeography of the indo-pacific parrotfish Scarus psittacus: Isolation generates distinctive peripheral populations in two oceans. Mar. Biol. 2010, 157, 1679-1691.

40. Hamrick, J.; Godt, M. Allozyme diversity in plant species. In Plant Population Genetics, Breeding, and Genetic Resources; Brown, A., Clegg, M., Kahler, A., Weir, B., Eds.; Sinauer: Sunderland, UK, 1989; pp 43-63.

41. Hobbs, J.-P.A.; Jones, G.P.; Munday, P.L. Extinction risk in endemic marine fishes. Conserv. Biol. 2011, 25, 1053-1055.

42. Hobbs, J.-P.A.; Jones, G.; Munday, P. Rarity and extinction risk in coral reef angelfishes on isolated islands: Interrelationships among abundance, geographic range size and specialisation. Coral Reefs 2010, 29, 1-11. 
43. Lewis, P.O.; Crawford, D.J. Pleistocene refugium endemics exhibit greater allozymic diversity than widespread congeners in the genus Polygonella (Polygonaceae). Am. J. Bot. 1995, 141-149.

44. Aleksić, J.M.; Geburek, T. Mitochondrial DNA reveals complex genetic structuring in a stenoendemic conifer Picea omorika [(panč.) purk.] caused by its long persistence within the refugial Balkan region. Plant System. Evol. 2010, 285, 1-11.

45. Voris, H.K. Maps of pleistocene sea levels in southeast asia: Shorelines, river systems and time durations. J. Biogeogr. 2000, 27, 1153-1167.

46. Froese, R.; Pauly, D. Fishbase. International centre for living aquatic resource management, manila. Available online: http://www.fishbase.org (accessed on 20 January 2013).

47. Torres-Díaz, C.; Ruiz, E.; González, F.; Fuentes, G.; Cavieres, L.A. Genetic diversity in Nothofagus alessandrii (Fagaceae), an endangered endemic tree species of the coastal Maulino forest of central Chile. Ann. Bot. 2007, 100, 75-82.

48. Fatemi, M.; Gross, C.L. Life on the edge-high levels of genetic diversity in a cliff population of Bertya ingramii are attributed to B. rosmarinifolia (Euphorbiaceae). Biol. Conserv. 2009, 142, 1461-1468.

49. Zidana, H.; Turner, G.F.; van Oosterhout, C.; Hänfling, B. Elevated mtDNA diversity in introduced populations of Cynotilapia afra (günther 1894) in Lake Malawi National Park is evidence for multiple source populations and hybridization. Mol. Ecol. 2009, 18, 4380-4389.

50. Bay, L.K.; Caley, M.J. Greater genetic diversity in spatially restricted coral reef fishes suggests secondary contact among differentiated lineages. Diversity 2011, 3, 483-502.

51. Hobbs, J.-P.A.; Salmond, J.K. Cohabitation of Indian and Pacific Ocean species at Christmas and Cocos (Keeling) Islands. Coral Reefs 2008, 27, 933-933.

52. Hobbs, J.-P.A.; Frisch, A.J.; Allen, G.R.; van Herwerden, L. Marine hybrid hotspot at IndoPacific biogeographic border. Biol. Lett. 2009, 5, 258-261.

53. Schultz, J.K.; Pyle, R.L.; DeMartini, E.; Bowen, B.W. Genetic connectivity among color morphs and pacific archipelagos for the flame angelfish, Centropyge loriculus. Mar. Biol. 2007, 151, 167-175.

54. Brothers, E.B.; Thresher, R.E. Pelagic duration, dispersal, and the distribution of Indo-Pacific coral reef fishes. In The ecology of coral reefs, Reaka, M.L., Ed.; NOAA: Washington, DC, USA, 1985; Volume 1, pp 53-70.

55. Stobutzki, I.C.; Bellwood, D.R. Sustained swimming abilities of the late pelagic stages of coral reef fishes. Mar. Ecol. Prog. Ser. 1997, 149, 35-41.

56. McMillan, W.O.; Palumbi, S.R. Rapid rate of control-region evolution in Pacific butterflyfishes (Chaetodontidae). J. Mol. Evol. 1997, 45, 473-484.

57. Bellwood, D.R.; Herwerden, L.; Konow, N. Evolution and biogeography of marine angelfishes (pisces: Pomacanthidae). Mol. Phylo. Evol. 2004, 33, 140-155.

58. Johannesson, K.; André, C. Life on the margin: Genetic isolation and diversity loss in a peripheral marine ecosystem, the Baltic sea. Mol. Ecol. 2006, 15, 2013-2029.

(C) 2013 by the authors; licensee MDPI, Basel, Switzerland. This article is an open access article distributed under the terms and conditions of the Creative Commons Attribution license (http://creativecommons.org/licenses/by/3.0/). 